УДК 025.5(100)(063)

ББК 78.54(0)л0

\title{
Будущее библиографии*
}

\section{II Международный библиографический конгресс}

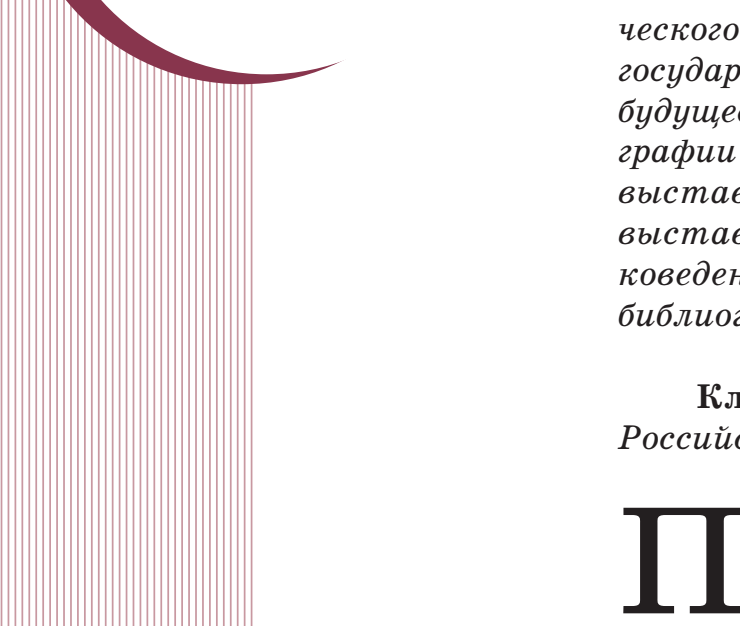

Ключевые слова: библиография, международный конгресс, Российская государственная библиотека. отечная ассоциация (РБА), Библиотечная Ассамблея Евразии, Российская государственная библиотека (РГБ), Российская национальная библиотека (РНБ), Российская книжная палата, Президентская библиотека им. Б.Н. Ельцина (ПБ). Заседания Конгресса проходили в Москве в РГБ, на базе Пермской государственной краевой универсальной библиотеки им. А.М. Горького была организована работа одной из секций в форме вебинара.

Решение о проведении нынешнего Конгресса было принято на заключительном заседании I Международного библиографического конгресса, проходившего в Санкт-Петербурге на базе РНБ $21-23$ сентября 2010 года. По его итогам РНБ издала трехтомник трудов Конгресса [5], в профессиональной печати был опубликован ряд статей [1-3].

II Международный библиографический конгресс собрал 903 участника (Москва -389 , Пермь -164 , в режиме вебинара на 78 площадках -350 человек). Делегаты представляли библиографическую общественность десяти стран: Беларуси, Болгарии, Израиля, Италии, Казахстана, Киргизии, России, США, Франции, Хорватии. Заседания транслировались на сайте Российской ассоциации электронных библиотек (http://www.aselibrary.ru/video/ conference43/conference436750/) и в YouTube. Было проведено три пленарных заседания, организована работа семи секций.

Пленарные заседания вели А.И. Вислый (генеральный директор РГБ), А.Ю. Самарин (заместитель генерального директора РГБ по научно-издательской деятельности), Н.К. Леликова (заведующая отделом РНБ), А.В. Теплицкая (заведующая отделом РГБ).

Возглавляли работу секций ведущие ученые и специалисты России: А.В. Соколов и Т.Ф. Лиховид, Н.Н. Каспарова и Е.И. Загорская, Н.К. Леликова и М.К. Сухоруков, А.А. Семенюк и А.А. Колганова, Л.Н. Зинчук и А.А. Кононов, М.Е. Бабичева и А.А. Копейкин, М.Ю. Нещерет и Н.И. Веденяпина, Н.М. Балацкая. Было заслушано

\footnotetext{
* При подготовке статьи использовались отчеты руководителей секций. Некоторые материалы Конгресса см.: Библиотековедение. - 2015. № 5 . - C. $8-30$.
} 
118 докладов, посвященных общетеоретическим и футурологическим проблемам библиографии; библиографической записи как основе формирования библиографических ресурсов; универсальным библиографическим ресурсам; информационнобиблиографическому обеспечению науки, техники, образования и культуры; библиографическому обеспечению свободного развития личности; информационно-библиографическому обслуживанию и обучению пользователей. Библиографы в Перми обсуждали стратегию развития краеведческой библиографии в современных условиях, опыт, проблемы и перспективы развития краеведческих библиографических изданий, доступность и качество электронных краеведческих библиографических ресурсов.

Была проведена специальная работа по формированию программы Конгресса. Больше всего заявок поступило на участие в работе секций, рассматривающих вопросы развития универсальных библиографических ресурсов, информационнобиблиографического обеспечения науки, техники, образования и культуры, информационно-библиографического обслуживания и обучения пользователей (от 30 до 45 докладов в каждой секции). Если на Конгрессе 2010 г. больше внимания было уделено истории, источниковедческому аспекту в библиографии, вопросам изучения книжной культуры, то на Конгрессе 2015 г. обсуждались проблемы будущего библиографии, работала специальная секция, посвященная вопросам формирования библиографической записи в современных условиях (ранее такой секции не было). Финансовые трудности не позволили увеличить число секций и расширить тематику, пришлось отказать некоторым коллегам в приеме заявок на выступления, так как они не укладывались в заявленные направления работы Конгресса.

На первом пленарном заседании выступили директора крупнейших библиотек и консорциумов, иностранные специалисты по проблемам формирования библиографической записи: В.П. Леонов, Библиотека Российской академии наук («“Голландская болезнь” российской библиографии»); М.Д. Афанасьев, Государственная публичная историческая библиотека России ( «Библиография и историческая наука»); Б.Р. Логинов, Национальный информационно-библиотечный центр «ЛИБНЕТ» («Современная технология национальной корпоративной каталогизации и ведение Сводного каталога библиотек России»); М. Виллер, Университет Задара в Хорватии
(«Стратегия обновления ISBD»); М. Гуэррини, Университет Флоренции в Италии ( $\mathrm{RDA}:$ новый стандарт для метаданных и поиска информационных ресурсов в цифровом мире»); В. Буле, Национальная библиотека Франции («Возобновление роли авторитетных данных для библиографических описаний в отношении с Веб: опыт Национальной библиотеки Франции»).

В работе Секции 1 "Общетеоретические и футурологические проблелы библиографии» (заявлено 24 доклада, заслушано 10) приняли участие преподаватели ведущих вузов, сотрудники национальных и муниципальных библиотек из Москвы, СанктПетербурга, Челябинска, Самары, Казани, Ярославля, Кемерово, Якутска, Тулы и других городов. Российские ученые и специалисты представили в своих докладах оригинальные авторские концепции сущности библиографии, особенности библиографоведения как науки, актуальные проблемы библиографической теории и практики. Большой интерес вызвали выступления, посвященные взаимосвязям библиографии и библиотечно-библиографической классификации, образовательной подготовке библиографических кадров для библиотек будущего, развитию исторической мысли в библиографической науке. В ходе дискуссии участники заседания секции пришли к некоторым выводам.

- Настоящий Конгресс, ориентированный на анализ современного состояния и будущее развитие библиографической теории и практики, имеет важное значение для консолидации и самосохранения библиографической профессии в неблагоприятных условиях господства технократической политики в библиотечно-библиографической отрасли. Происходит дезорганизация национальной библиографической системы, разрушение подготовки библиографических кадров в высшей школе, отрицается ценность библиографической науки.

- Библиография является инфраструктурной составляющей библиосферы, обеспечивающей нормальное функционирование библиотечного, книгоиздательского, книготоргового дела, поэтому в проектах информатизации разработку и внедрение библиографической системы необходимо рассматривать как приоритетную задачу. Вызывает беспокойство недостаточное внимание к библиографическому поиску в проекте Национальной электронной библиотеки (НЭБ), компрометирующее саму ее идею. 
- Современное библиографоведение представляет собой продвинутую в теоретическом и методологическом отношении научную дисциплину информационно-документального цикла наук. Развитие библиографической теории способствует обогащению взаимодействующих с ней библиотековедческих и книговедческих дисциплин. В настоящее время Российской книжной палате сложно выполнять функции головной организации российской библиографической системы. Вспоминая традиции Русского библиографического общества и Русского библиологического общества, участники заседания считают целесообразным активизировать усилия библиографического сообщества по организации и развитию библиографической науки и практики в нашей стране.

- В период перехода российского общества от индустриальной цивилизации к постиндустриальной, библиографическая деятельность должна приобрести гуманистическую направленность, чтобы обеспечить поиск, систематизацию, распространение гуманистических ценностей, воплощенных в документных потоках и фондах. Библиография - незаменимая и необходимая инфраструктура в условиях риска дегуманизации России.

На заседании Секиии 2 "Библиографическая запись как основа формирования библиографических ресурсов» было заслушано 13 докладов (заявлено 14), в том числе 3 доклада представлены на пленарном заседании. Докладчики представляли Россию (Москва и СанктПетербург), Италию, Францию, Хорватию, Казахстан. Наибольшую активность проявили специалисты учреждений, входящих в систему Российской академии наук (5 докладов). На секции рассматривались следующие темы: развитие нормативно-методической базы каталогизации на международном и национальном уровнях; язык библиографической записи и многоязычие в электронном каталоге (ЭК); особенности каталогизации некоторых видов ресурсов (мультимедийных, законодательных материалов, академических изданий); авторитетный контроль в ЭК и формирование авторитетных файлов в библиотеках разного уровня - национальных и международных; особенности библиографирования и лингвистического обеспечения библиографических ресурсов (указателей). Неоднозначно был воспринят доклад о семантических средствах в ЭК РГБ, вызвавший дискуссию. Также обсуждались и вопросы ретроспективной конверсии карточных каталогов.

Секция рекомендовала продолжить развивать нормативно-методическую базу каталогизации с учетом новых концептуальных моделей и международных стандартов; осуществлять мониторинг международных и активизировать собственные научные исследования по изучению функций библиографической записи в среде «Семантический Веб» .

На Секиии 3 «Универсальные библиографические ресурсы» планировалось заслушать 28 выступлений представителей Беларуси, России, США, Узбекистана, но 7 докладчиков не смогли приехать на Конгресс. На заседании обсуждался следующий круг вопросов: регламентация деятельности в области текущей национальной библиографии на международном уровне; российское законодательство об обязательном экземпляре и отражение документов, поступающих по обязательному экземпляру, в текущей национальной (государственной) библиографии, проблемы исполнения закона на региональном уровне и вопросы совершенствования законодательства применительно к современной информационной среде; состояние и перспективы развития ретроспективной национальной библиографии Российской Федерации в целом и в национальных республиках - субъектах РФ, в частности; создание национальных библиографических репертуаров и сводных каталогов местной печати как одно из приоритетных на- 
правлений в развитии российской библиографии; библиографирование изданий русского зарубежья и экстериорики как способ объединения знаний о книжной культуре русского народа; общие проблемы создания библиографической продукции, формирования ресурсов, реализация библиографических проектов на пространстве СНГ и внутри России, библиографическое отражение фондов, собраний, коллекций библиотек, в частности коллекции редких изданий ПБ, фонда Отдела газет РГБ, электронные ресурсы публичных библиотек (на примере Центральной городской публичной библиотеки (ЦГПБ) им. В.В. Маяковского в Санкт-Петербурге).

Участники секции выработали ряд рекомендаций:

- обратить внимание на необходимость в полной мере выполнять требования закона «Об обязательном экземпляре документов» на федеральном и особенно на региональном уровнях, поскольку ненадлежащее исполнение закона издающими организациями ведет к лакунам в национальном библиографическом учете документов;

- в целях совершенствования указанного законодательства рассмотреть вопрос о подготовке дополнительного акта, предусматривающего обязательный экземпляр сетевых электронных ресурсов, на первом этапе - электронных книг и сетевой научной периодики; в соответствии с рекомендациями ИФЛА предлагается не включать в Федеральный закон «Об обязательном экземпляре документов» электронные копии печатных изданий и другие аналоговые ресурсы;

- считать приоритетным направлением развития современной отечественной библиографии национальный библиографический учет издательской продукции, в том числе учет изданий, выпущенных на территории отдельных краев и областей Российской Федерации;

- обратить внимание на необходимость сохранения и дальнейшего развития библиографии изданий экстериорики и русского зарубежья;

- считать необходимым отметить, что в соответствии с международными рекомендациями к данным национальной (государственной) библиографии (текущей и ретроспективной) должен обеспечиваться свободный бесплатный доступ;

- указать на необходимость текущего библиографирования электронных сетевых библиографических ресурсов (библиография библиографии), в первую очередь краеведческих ресурсов и местной печати.

Участвовать в работе Секиии 4 «Инфорлаиионно-библиографическое обеспечение науки, техники, образования и культуры» с докладами выразили готовность наибольшее число делегатов Конгресса - 45 (заслушано 28 докладов). Это библиографы России, Беларуси, Болгарии. Россию представляли сотрудники федеральных, реги- ональных, академических, учебных библиотек Москвы, Санкт-Петербурга, Красноярска, Новосибирска, Екатеринбурга, Томска, Архангельска, Якутска, Самары, Барнаула, Перми, Волгограда, Омска.

Круг обсуждаемых проблем был достаточно широким: современная библиография в цифровом пространстве и библиографические ресурсы по отдельным направлениям науки и культуры; роль современного методологического аппарата в создании базовой модели системы информационного обеспечения пользователей любого уровня (от студента до ученого-исследователя); внедрение компьютерных технологий в библиографическую деятельность с целью решения проблемы более быстрого, глубокого и тщательного информационного обеспечения искусства и науки и облегчения поиска литературы, доступа к библиографическим ресурсам широкому кругу ученых, преподавателей, студентов; вебиблиографические пособия и вопросы каталогизации интернет-ресурсов (в частности, информационных сайтов по культуре и образованию); биографика деятелей книжной культуры.

Рассматривались также вопросы библиографического обеспечения работы межбиблиотечного абонемента и электронной доставки документов, места библиометрических исследований в структуре справочно-библиографического обслуживания, когда на основе общих и специальных методов библиометрических исследований могут быть подготовлены любые информационные продукты (от простой справки до серьезного библиографического указателя). Анализ докладов показал, что практически везде поднимается необходимость решения возникающих вопросов, связанных с цифровыми ресурсами. Подчеркивалась идея огромных возможностей электронной среды в профессиональной деятельности библиографов, приоритетная роль цифровых технологий в обеспечении современных научных исследований.

Можно констатировать, что в обществе существует устойчивый спрос на информационнобиблиографические услуги, особенно это относится к возникшей в последние годы потребности в проведении библиометрических исследований и оценке научно-публикационной активности организаций и авторов. $K$ сожалению, существует проблема недооценки государством роли библиотек, в частности специалистов-библиографов, в осуществлении информационного сопровождения научных исследований. Необходима организация библиографического обслуживания в соответствии с тенденциями мирового информационного процесса. Выявилась потребность в углубленном корпоративном взаимодействии некоторых специализированных библиотек (например, библиотек для слабовидящих). 
В ходе работы Секции выработаны следующие предложения:

- создать единый общероссийский портал «Библиографические ресурсы России» для максимальной координации библиографических коллективов России в подготовке конкурентоспособных (на мировом уровне) информационно-библиографических ресурсов; обеспечить участие библиографов в создании отечественных ресурсов РИНЦ (Научная электронная библиотека eLIBRARY.RU), «Карта российской науки» (Государственная публичная научно-техническая библиотека России) и координацию работы с международными библиографическими ресурсами;

- как можно скорее подготовить к печати сборник трудов конгресса (или его цифровой аналог), включив в него все контакты для последующего общения с авторами;

- рассмотреть возможность организации онлайновых встреч по актуальным вопросам библиографии в период между конгрессами, для этих целей создать рабочую межсекционную группу на уровне РБА.

На заседании Секиии 5 «Библиографическое обеспечение свободного развития личности» было представлено 10 докладов (заявлено 19) из Москвы, Тамбова, Златоуста. Основной темой обсуждения стала рекомендательно-библиографическая деятельность библиотеки как социокультурного института. Доклады были сгруппированы по тематике в три больших блока: общетеоретические вопросы рекомендательной библиографии, рекомендательная библиография для детей, рекомендательная библиография в информационной среде.

Итогом работы Секции стало создание общих алгоритмов взаимодействия в области осуществления рекомендательно-библиографической деятельности в стенах библиотеки и от ее имени. Определены перспективы и планы (в том числе совместные) реализации рекомендательно-библиографической функции библиотеки как социокультурного института.

На Секции 6 «Инфорлационно-библиографическое обслуживание и обучение пользователей» было заслушано 24 доклада (из 32 заявленных), отразивших опыт работы библиотек в области библиографического обслуживания и обучения пользователей Беларуси, России, США. Проблемы повышения эффективности деятельности справочнобиблиографических служб в условиях масштабных изменений, происходящих в стране и мире, докладчики рассматривали через призму новой парадигмы отношений: человек - информация - общество.

По форме и содержанию доклады были сгруппированы в несколько условных тематических блоков: новые формы и методы библиографического обслуживания; практика справочно-библиографической работы (опыт деятельности конкретных справочно-библиографических служб); организация справочно-поискового аппарата; создание и использование электронных ресурсов; информационная поддержка специалистов и обучение библиографическому поиску; мониторинг и учет результатов библиографического обслуживания. Существенное внимание было уделено вопросам оптимальной организации базы информационного обслуживания, необходимости создания инструментов управления библиографическими ресурсами, подготовки специалистов-библиографов, в совершенстве владеющих технологиями поиска.

Доклады, освещающие практику обслуживания удаленных пользователей посредством виртуальных справочных служб и организации текущего и упреждающего информирования специалистов с использованием современных систем коммуникации, получили живой отклик у аудитории. Особый интерес вызвал опыт ЦГПБ им. В.В. Маяковского Санкт-Петербурга по внедрению новых стандартов информационно-библиографического обслуживания, а также по проведению внутреннего аудита этого направления деятельности.

Ряд докладов был посвящен культурно-просветительской функции библиографических служб. Выступающие говорили о роли библи- 
ографов-профессионалов в обучении специалистов различных областей деятельности методам ориентации в информационном пространстве, в том числе с использованием таких инструментов, как инфолоция и библио-эдвайзер. Участники секции ознакомились с новыми приемами популяризации библиографических знаний: информационным марафоном, библиографическим биеннале, информационным брифингом.

С большим интересом были заслушаны доклады на тему перспектив развития библиографических служб библиотек - на основе расширения спектра справочно-библиографических услуг, заимствования передовых технологий, в том числе из смежных областей деятельности, эффективных форм взаимодействия с пользователем. Оживленные дискуссии вызвало обсуждение путей преодоления кризисной ситуации, связанной с оттоком пользователей из библиотеки.

Представленные доклады продемонстрировали многообразие функций, выполняемых библиографами, высокий уровень креативности справочно-библиографических служб, их непреходящее стремление к совершенствованию, поиску инновационных решений проблем информационного обслуживания, готовность к освоению современных технологий библиографического поиска и желание делиться своими знаниями с пользователями библиотек - специалистами, преподавателями вузов, студентами и аспирантами.

Секиия 7 "Краеведческая библиография» работала в режиме вебинара. Основной площадкой ее проведения стала Пермская государственная краевая универсальная библиотека им. А.М. Горького. Докладчики находились в разных городах России (в том числе и в РГБ). Было заявлено 10 докладов (заслушано 9).

Рассматривались вопросы стратегии краеведческой библиографии в цифровой среде: проблемы избытка и недостатка информации, повышения привлекательности форм представления библиографических ресурсов на сайтах библиотек, развития краеведческой библиографии в бумажной и электронной формах, экстериорики. Выступления отражали опыт РНБ, национальных библиотек Ингушетии, Башкортостана, Чувашии, Алтайской краевой универсальной научной библиотеки им. В.Я. Шишкова, вузовских и общедоступных муниципальных библиотек Пермского края. Участники заседания отметили особую важность специальной разработки следующих тем: источники, методы выявления и использование экстериорики в кра- еведческой библиографии, современные и привлекательные формы представления крупных массивов библиографической информации, определение стратегии первичного библиографического учета краеведческих документов.

На заключительном пленарном заседании были подведены итоги работы Конгресса, намечены пути развития библиографии на ближайшую перспективу. Специально для участников были подготовлены две выставки: книжная «Библиография России (2011-2015)» и виртуальная «Всероссийский конкурс научных работ по библиотековедению, библиографии и книговедению (библиографоведение и библиографическая продукция). Лауреаты XXI века» (http://presentation.rsl.ru/ presentation/view/73).

На основе книжной выставки можно было проследить развитие библиографии в России за последние пять лет - между двумя Международными библиографическими конгрессами. Экспозиция состояла из пяти разделов: Общий раздел; Лауреаты Всероссийского конкурса научных работ по библиотековедению, библиографии и книговедению (библиографоведение и библиографическая продукция); Научные монографии и сборники научных трудов; Учебники, учебные и практические пособия; Библиографические указатели и каталоги.

Открывали экспозицию Труды I Международного библиографического конгресса, изданные в трех томах, ведущие журналы профессионального библиографического сообщества. Далее были представлены работы лауреатов Всероссийского конкурса научных работ по библиотековедению, библиографии и книговедению (библиографоведение и библиографическая продукция). Этот конкурс уже давно завоевал признание профессионалов. Один раз в два года жюри выбирает лучшие работы из сотен изданий, присланных на конкурс. Библиографоведческая литература за прошедший период пополнилась рядом замечательных трудов классиков отечественной библиографии. Был переиздан (с обширными комментариями) фундаментальный труд Н.В. Здобнова «История русской библиографии от древнего периода до начала XX века». Ведущие библиографические центры страны опубликовали очередные выпуски научных продолжающихся изданий. Учебная литература пополнилась новыми учебниками, в том числе по библиографии, предназначенными для преподавателей и студентов бакалавриата библиотечно-информационных факультетов вузов. 
Вышло четвертое издание, значительно переработанное, «Справочника библиографа». Большую часть экспозиции занимали библиографические указатели и каталоги, подготовленные библиотеками России. И это только маленькая часть из созданных библиографическим сообществом пособий. За рамками выставки также остались библиографические ресурсы, реализованные в электронном формате.

Книжную экспозицию дополняла фотовыставка «Путешествие по

II Международный библиографический конгресс библиотекам мира». Автор проекта и всех фоторабот - путешествующий библиотекарь из Мончегорска Светлана Мамакина. На фотографиях запечатлены крупнейшие и небольшие библиотеки России и других стран.

На виртуальной выставке представлены 35 библиографических изданий и научных исследований по библиографоведению, которые стали лауреатами Всероссийского конкурса по библиотековедению, библиографии и книговедению в $2001-2013$ гг. по различным номинациям.

Специально к началу работы Конгресса издательство «Пашков дом» опубликовало книгу «Отечественные библиографы и библиографоведы» (см. с. 43), подготовленную в НИО библиографии РГБ [4]. В ходе заседаний Конгресса было высказано предложение рекомендовать этот указатель для участия во Всероссийском конкурсе по библиотековедению, библиографии и книговедению.

Участники Конгресса высоко оценили уровень его организации и выразили единодушное желание продолжить традицию проведения таких форумов, поскольку благодаря осмыслению и освоению опыта коллег значительно повышается профессиональный уровень каждого из участников, появляется возможность установить личные профессиональные контакты.

\title{
Список источников
}

1. Бакун Д.Н.Международный библиографический конгресс: 100 лет спустя // Книга. Исследования и материалы. - 2010. - Сб. 93/1-2. - С. 203-208.

2. Леликова H.К. Международный библиографический конгресс // Библиография. -2010 . - № 6. - С. 117-130.

3. Леликова H.K. Международный библиографический конгресс / Н.К. Леликова, А.В. Теплицкая, Г.Л. Левин // Библиотековедение. 2010. - № 6. - C. $14-19$.

4. Отечественные библиографы и библиографоведы : указ. док. источников и лит. о жизни и деятельности, 1917-2014 / Рос. гос. б-ка, Науч.исслед. отд. библиогр. ; [сост.: Г.Л. Левин, А.В. Теплицкая, при участии Н.И. Трофимовой]. - Москва : Пашков дом, 2015. - 621, [1] с., 16 ил. (Деятели отечественного библиотековедения и библиографоведения).

5. Труды Международного библиографического конгресса (Санкт-Петербург, 21-23 сент. 2010 г.) / Рос. нац. б-ка. - Санкт-Петербург, 2012. - Ч. 1. 496 с. ; Ч. 2. -424 c. ; Ч. $3 .-488$ c.

Иллюстративный латериал предоставлен автором статьи

\author{
А.В. Теплицкая, \\ заведующал Научно-исследовательским \\ отделом библиографии \\ Российской государственной библиотеки, \\ кандидат педагогических наук, доиент \\ Контактные данные: \\ 119019, Москва, ул. Воздвиженка, д. 3/5; \\ e-mail:TeplitskayaAV@rsl.ru
}

